\title{
Excelência criativa em mulheres brasileiras
}

\section{Creative excellence in Brazilian women}

\section{La excelencia creativa en las mujeres brasileñas}

\author{
Maria Célia Bruno Mundim* \\ Pontifícia Universidade Católica de Campinas - PUC-Campinas, Campinas, São \\ Paulo, Brasil
}

\section{Solange Muglia Wechsler**}

Pontifícia Universidade Católica de Campinas - PUC-Campinas, Campinas, São Paulo, Brasil

\begin{abstract}
RESUMO
Considerando o aumento de mulheres em posição de destaque nos diversos setores da sociedade, esta pesquisa buscou investigar os estilos de pensar e criar, e verificar as diferenças nos fatores ambientais e psicológicos que influenciam a excelência criativa de mulheres brasileiras em diferentes áreas. A amostra foi composta por 20 mulheres (11 reconhecidas por excelência criativa por meio de premiações e 9 não reconhecidas por excelência criativa e sem premiações). Os instrumentos foram um Roteiro de Entrevista, a Escala de Estilos de Pensar e Criar e um Roteiro de Análise de Produção Criativa. O teste Mann-Whitney foi utilizado para comparar as diferenças existentes entre as mulheres com excelência criativa e as não criativas. Quanto às entrevistas, foi feita uma análise de conteúdo e utilizado - Qui-quadrado para as categorias de respostas. Houve diferenças significativas entre os dois grupos de mulheres nos conteúdos das entrevistas. Conclui-se sobre a importância de conhecer os fatores que auxiliam o alcance da excelência.
\end{abstract}

Palavras-chave: talento, gênero, criatividade, excelência, mulher.

\begin{abstract}
Considering the increasing number of prominent women in the various sectors of society, this research aimed to investigate their styles of thinking and creativity and to verify differences in the environmental and psychological factors that influence the creative excellence of Brazilian women in different areas. The sample were 20 Brazilian women (11 recognized for creative excellence through awards and 9 not recognized for creative excellence and without awards). The instruments were a Interview Guide, the Thinking and Creating Styles Scale and a Creative Production Analysis Guide. The Mann-Whitney test was used to compare differences between women with creative excellence and not creative. As for the interviews, a content analysis was carried out and the Chi-squared distribution was used for the categories of answers. There were significant differences between the two groups of women in the interview content. It
\end{abstract}


was concluded on the importance of knowing the factors that help achieve excellence.

Keywords: talent, gender, creativity, excellence, woman.

\section{RESUMEN}

Teniendo en cuenta el creciente número de mujeres en posiciones destacado en los diversos sectores de la sociedad, esta investigación investiga los estilos de pensar y de crear y verifica diferencias en los factores ambientales y psicológicos que influyen en la la excelencia creativa de las mujeres brasileñas en las diferentes áreas. La muestra consistió en 20 mujeres (11 reconocidos por la excelencia creativa através de premios y 9 no reconocidos por la excelencia creativa y no hay premios). Los instrumentos fueron una Guía de Entrevista, la Escala de Estilos de Pensar y Crear y una Guía de Análisis de Producción Creativa. Se utilizó la prueba de Mann-Whitney para comparar las diferencias entre las mujeres con la excelencia creativa y no creativas. En cuanto a las entrevistas, se realizó un análisis de contenido y utilizado el Chi-cuadrado para las categorías de respuestas. Hubo diferencias significativas entre los dos grupos de mujeres en el contenido de las entrevistas. Se concluye sobre la importancia de conocer los factores que ayudan a llegar la excelencia.

Palabras clave: talento, género, creatividad, excelencia, mujer.

\section{I ntrodução}

Atualmente a excelência humana tem sido um tema frequente na literatura PSI internacional (Cianciolo et al., 2006; Ericsson \& Lehmann, 1996; Sternberg, 2001; Trost, 2000), entretanto existe carência de pesquisas sobre a excelência criativa em mulheres. Portanto, torna-se necessário investigar mais as condições ou fatores que favorecem a excelência criativa em mulheres brasileiras de diferentes áreas.

Por excelência entende-se o desempenho superior do indivíduo, que supera as expectativas e cria novas possibilidades em determinada área de atuação (Garcia-Santos, Almeida, \& Werlang, 2012). Tal desempenho e realização excepcional em um domínio específico como, por exemplo, esportivo, musical ou artístico, normalmente resulta na eminência dentro desse domínio, tal como uma medalha de ouro olímpico ou uma aclamação pela crítica (Simonton, 2008). Para Puccio, Murdock e Mance (2007) as ideias e produtos desenvolvidos por uma pessoa criativa vão exercer comoção imediata ou futura sobre um campo, exercendo desta maneira uma liderança, de forma indireta, sobre uma área específica. Assim sendo, a pessoa criativa acaba por ser reconhecida socialmente por sua criatividade, que conduziu à inovação e alterações favoráveis ao cotidiano em diversas culturas (Runco, 2007).

Dentre os fatores que influenciam a criatividade feminina está o ambiente familiar e as barreiras impostas pela sociedade (Wechsler, 2008a). Os comportamentos femininos de subordinação e 
dependência adquiridos no ambiente familiar, por exemplo, são esperados para o sexo feminino desde a infância à idade adulta, pois a mulher é mais voltada ao cuidado das pessoas do que o homem (Dessen, 1997; Ramos, 2008). De outro modo, pesquisa sobre mulheres criativas brasileiras realizada por Wechsler e Guerreiro (1986) apontou que estas apresentavam estados de conflito na identificação com a mãe. Além disto, foi observado que estas mulheres enfrentavam barreiras externas impostas pela sociedade, assim como internas, tais como o medo do sucesso e o sentimento de engano (relacionado com a baixa autoestima).

Embora haja indicadores comportamentais na criança potencialmente criativa tais como a independência de pensamento, a autonomia, 0 comportamento original e espontâneo (Runco, 2006), a família é o fator que mais causa impacto sobre o desenvolvimento do talento dos jovens conforme estudo realizado por Chagas e Fleith (2011). As atitudes parentais, tais como o incentivo à imaginação, o estímulo à exploração dos interesses da criança, o incentivo à autoconfiança e à autonomia favorecem o desenvolvimento criativo dos filhos (Alencar \& Fleith, 2003; Krumm, Vargas-Rubilar, \& Gullón, 2013). Também o comportamento criativo dos pais e o fator multicultural familiar facilita o aparecimento da criatividade de seus descendentes (Chang, Hsu, Shih, \& Chen, 2014; Leung, Maddux, Galinsky, \& Chiu, 2008).

Estudos biográficos de pessoas eminentemente criativas de Barron e Harrington (1981), e Plucker e Renzulli (1999) verificaram que a capacidade de liderança e a sensibilidade interna e externa eram características de personalidade mais presentes nestas mulheres. Outros atributos presentes nestas pessoas eram: flexibilidade de pensamento, fluência, originalidade, ideias elaboradas, sensibilidade interna e externa/ intuição, fantasia, alta motivação, sentido de humor, impulsividade, espontaneidade, autoconfiança, inconformismo, preferência por situações de risco, independência de julgamento, persistência, linguagem metafórica, abertura à novas experiências, capacidade de liderança, honestidade, otimismo, atitude visionária, curiosidade, dinamismo, sentido de destino criativo, sensibilidade ambiental, atração pela complexidade, tolerância às frustrações (Dacey, 1998; Morais, 2001; Runco \& Pritzker, 2011; Wechsler, 2008a). A psiquiatra Nise da Silveira, por exemplo, foi considerada uma pessoa altamente criativa e apresentou várias destas características (Oliveira \& Nakano, 2014).

A pessoa criativa, sua energia e seu trabalho árduo, bem como suas características de personalidade tais como alta imaginação e questionamento, independência de julgamento social e desejo por autonomia a favorecem a inovar (Cotec, 2012; Patterson, Kerrin, \& Gatto-Roissard, 2012). Por outro lado, estudos tem evidenciado que o processo criativo e, principalmente, a incubação possibilita que as 
pessoas criativas realizem descobertas relevantes (Sio \& Rudowicz, 2007).

Outro aspecto próprio da pessoa criativa diz respeito ao tipo de motivação que a conduz para certa atividade. Nesse sentido, Amabile (1996) destaca a motivação intrínseca que refere ao engajamento e contentamento que o indivíduo tem pela atividade, livre de reforços ambientais, podendo levá-lo ao desenvolvimento de habilidades de domínio e ao desenvolvimento da criatividade. Também a alta energia psíquica e física, a curiosidade e o interesse fazem com que estas pessoas trabalhem por longas horas, usufruindo e sentindo prazer com o trabalho, o que é denominado por Csikszentmihalyi (1997) como estados de flow (ou fluxo).

No que refere as mulheres altamente criativas, Rieger e Blabergs (1979) concluíram, em revisão da literatura, que elas tendem apresentar traços de personalidade semelhantes - originalidade, flexibilidade, tolerância a ambiguidade, autoconfiança, persistência, teimosia, independência, necessidade de correr riscos e experimentar - independente da área profissional em que atuam. Além disso, as autoras chegaram a conclusão de que aquelas mulheres apresentam características de personalidade semelhantes aos homens altamente criativos, além de serem menos parecidas com as mulheres menos criativas, não correspondendo ao papel de gênero estereotipado. Portanto, atenção deve ser dada ao estilo de criar dessas mulheres.

Por estilos entende-se as maneiras preferenciais de pensar e se comportar frente a determinadas situações (Wechsler, 1999, 2006). Por outro lado, para Kirton $(1976,1994)$ os estilos de criar são "preferências cognitivas consistentes e estáveis que se manifestam em qualquer situação envolvendo criatividade, solução de problemas e tomada de decisão" (p.37). Ele criou a Teoria Adaptador Inovador, na qual os indivíduos adaptadores são descritos pela precisão, confiança, prudência, conformidade, disciplina, detalhismo, eficiência, optam por soluções conhecidas e acatam normas grupais ao usarem a criatividade. Por sua vez, os indivíduos inovadores são percebidos como contestadores, indisciplinados, pensadores, criadores, visionários, gostam de arriscar-se com ideias diferentes e tendem a ignorar hábitos e padrões.

Com a falta de instrumentos adaptados à nossa realidade que avaliam os estilos de criar, Wechsler $(1999,2006)$ desenvolveu uma escala chamada "Escala de Estilos de Pensar e Criar", aprovada pelo Conselho Federal de Psicologia. Em um estudo recente foi feita análise da dimensionalidade dos cinco estilos de criar do instrumento e de sua validade externa (Wechsler, Vendramini, \& Oaklan, 2012). 1.752 brasileiros participaram do primeiro estudo (55\% mulheres) e 128 no segundo estudo ( $53 \%$ mulheres), entre os quais $45 \%$ haviam demonstrado talento criativo. Os instrumentos foram uma escala de estilos de pensar e criar e os testes verbal e figural de Torrance. Para 
análise de itens foi utilizado o modelo de Rasch e como resultado dois estilos foram identificados: Cauteloso-Reflexivo e InconformistaInovador. A regressão linear para predizer realizações criativas reconhecidas indicou as contribuições significativas dos fatores de criatividade verbal e do estilo Inconformista-Inovador. Assim sendo, os estilos foram considerados como tendo validade.

Em outro estudo brasileiro (Mundim \& Wechsler, 2007), constatou-se que os gerentes de grandes empresas demonstraram ter estilos de criar mais ousados e inconformistas, além de utilizarem mais a intuição do que seus subordinados, sendo esta última característica mais predominante entre as mulheres. Já no estudo de Martins (2009) com gerentes e subgerentes de micro e pequenas empresas foi verificado que tanto os gerentes quanto os subgerentes de ambos os gêneros apresentaram maior predomínio do estilo de pensar lógico-objetivo.

Tendo em vista o aumento da quantidade de mulheres em posição de destaque nos diversos setores da sociedade, o objetivo deste estudo foi investigar os estilos de pensar e criar e os fatores ambientais e psicológicos que influenciam a produção criativa de mulheres consideradas como excelência em criatividade nas mais diversas áreas.

\section{Método}

\subsection{Participantes}

A amostra foi constituída por 20 mulheres, sendo 11 delas reconhecidas como excelência em criatividade e 9 não reconhecidas, que atuavam em diferentes áreas de atuação da região Sudeste do Brasil. A idade média destas mulheres foi de 49,30 anos, com desvio padrão de 8,29 , sendo que a idade mínima foi de 35 anos e a máxima de 66 anos.

O critério de inclusão de excelência em criatividade foi de ter sua produção reconhecida socialmente por meio de pelo menos uma premiação e/ou distinção em seus campos de atuação, podendo ser em nível local, estadual, nacional ou internacional. O grupo de mulheres não reconhecidas como excelência foi composto por aquelas sem premiação e honras, mas atuando na mesma área profissional do grupo de mulheres reconhecidas em criatividade.

Também houve a participação de dois juízes, alunas de pósgraduação da PUC-Campinas com nível de mestrado que colaboraram no estudo para investigar as evidências de validade de conteúdo das categorias de respostas dos sujeitos na entrevista. 


\subsection{I nstrumentos}

O material utilizado na pesquisa foi composto por: Escala de Estilos de Pensar e Criar, o Roteiro de Entrevista e o Roteiro de Análise de Produção Criativa.

A Escala de Estilos de Pensar e Criar (Wechsler, 2006) é composta por 100 itens, com frases positivas e negativas, que devem ser respondidas no formato Likert com 6 pontos (discordo totalmente, discordo, discordo parcialmente, concordo parcialmente, concordo, concordo totalmente). A validade da estrutura interna da escala de Wechsler foi observada através da análise fatorial com 1.752 indivíduos, que apontou a existência de cinco estilos de pensar e criar, explicando $36 \%$ da variância. A composição destes estilos foi a seguinte: 1) Estilo Cauteloso-Reflexivo caracterizado por indivíduos que apresentam preferência por prudência, reflexão e ordem; 2) Estilo Inconformista-Transformador que define aquele que questiona regras de pensar e agir e gosta de resolver problemas de maneira incomum; 3) Estilo Lógico-Objetivo caracterizado pelo pensamento lógico, racional e pragmático; 4) Estilo Emocional-Intuitivo que caracteriza-se pelo predomínio das emoções e das intuições em suas ações e, por fim, 5) Estilo Relacional-Divergente que descreve a pessoa flexível e com facilidade para liderar grupos, pois procura atender as opiniões de seus membros.

A validade da escala por critério externo foi feita comparando-se os resultados de 128 indivíduos que tinham recebidos premiações com os cinco estilos definidos, demonstrando correlações significativas entre estilos e produção criativa. Também foi observado que os estilos criativos podiam identificar pessoas que tiveram a criatividade reconhecida por meio de prêmios recebidos daqueles indivíduos que não obtiveram nenhuma premiação. A precisão da escala variou de 0,60 a 0,90 , pelo coeficiente Alpha, sendo mais alta para os três primeiros estilos.

O Roteiro de Entrevista (Wechsler, Romo, Morais \& Ferreira, 2013) é composto por quinze questões semi-abertas relacionadas à infância, adolescência, carreira, processo de trabalho, mudanças observadas no trabalho com o passar dos anos, obstáculos/bloqueios pessoais, identificação de jovens talentosos na área de atuação, administração da vida pessoal e profissional, desafios na atualidade e tempo livre. $O$ roteiro foi baseado no modelo do protocolo de entrevista elaborado por Csikszentmihalyi (1997), em pesquisas com indivíduos reconhecidos como criativos.

O Roteiro de Análise de Produção Criativa (Wechsler, 2004) contém dez questões fechadas e uma aberta sobre a produção artística, científica e cultural do indivíduo. As questões referem-se às Artes Plásticas, Literatura, Música, Teatro, Esporte, Publicação e Descoberta Científica e ao tipo (ou não) de reconhecimento por meio 
de premiação ou distinção local, regional, nacional e/ou internacional. Assim sendo, este instrumento possibilita a avaliação de três fatores: 1) produção não reconhecida - quantidade de produtos julgados como criativos pelo indivíduo, mas sem nenhuma distinção/premiação; 2) produção reconhecida - quantidade de produtos premiados ou com distinções; 3) produção total - soma da produção não reconhecida com a reconhecida. Cada produto citado como produção reconhecida ou não reconhecida ganha 1 ponto. Este material foi baseado no inventário utilizado por Torrance (1981) em seus estudos longitudinais sobre a pessoa criativa e a produção criativa com a finalidade de conseguir um indicador válido da produção real do sujeito. Esta avaliação permite indicar as pessoas reconhecidas socialmente como criativas, bem como aquelas potencialmente criativas que ainda não foram reconhecidas pela sociedade.

\subsection{Procedimento}

Após aprovação do projeto pelo Comitê de Ética em Pesquisa do Centro de Ciências da Vida da PUC-Campinas, a pesquisadora buscou obter informações (por meio de sites de busca na internet, contatos pessoais e indicações) sobre as mulheres que se destacaram e receberam prêmios em suas áreas de atuação e contatou cada mulher por meio de telefone e/ou e-mail com o objetivo de apresentar a proposta da pesquisa, esclarecer possíveis dúvidas e convidá-las a participar da pesquisa. As mulheres excelentes criativas/premiadas foram indicadas por conhecidos. Por sua vez, estas também indicavam outras em suas áreas. Quanto a maioria daquelas sem premiações ou honras foram encontradas por meio de dados pesquisados na web.

As mulheres excelentes criativas/premiadas e não premiadas assinaram o Termo de Consentimento Livre e Esclarecido (TCLE), aceitando participar, voluntariamente, do estudo. Depois foram marcadas e realizadas entrevistas individuais e aplicados todos os instrumentos em suas residências, ateliês ou salas privadas de trabalho (no caso das professoras universitárias). A média de duração da entrevista juntamente aos instrumentos foi de duas horas.

Para a análise estatística da Escala de Estilos de Pensar foi utilizado o teste Mann-Whitney para comparar as médias dos fatores entre os grupos de excelentes criativas/premiadas e não premiadas. Para o Roteiro de Análise de Produção Criativa foi dado um ponto à cada ocorrência de produção reconhecida e não reconhecida e depois toda pontuação somada. Em seguida foi utilizada a Correlação por Postos de Spearman entre os fatores da Escala de Estilos de Pensar e Criar e da Produção Criativa das excelentes criativas/premiadas e não 
premiadas para a verificação do inter-relacionamento das variáveis consideradas.

Quanto ao Roteiro de Entrevista foi utilizada a Análise de Conteúdo. Primeiro todas as respostas das participantes excelentes criativas/premiadas foram categorizadas segundo o sistema de Bardin (2011) (pela frequência de aparecimento de itens). Depois os temas foram agrupados em categorias mais amplas. Estas categorias serviram de base para comparação com as categorias de respostas das participantes não premiadas. Posteriormente, procedendo a validade de conteúdo, dois juízes de Psicologia foram convidados e leram uma entrevista de uma mulher excelente criativa/premiada para análise com auxílio das categorias anteriores já levantadas. O grau de concordância entre os juízes foi realizado por meio do coeficiente Kappa.

A fim de analisar se existiam diferenças significativas entre as proporções de respostas das excelentes criativas/premiadas e não premiadas foi utilizado o Qui-quadrado e o teste de Cochran-MantelHaenzel foi aplicado para a comparação das categorias/subcategorias entre as mulheres excelentes criativas/premiadas e não premiadas. Este teste é um tipo de Qui-quadrado, adequado à estudos de associação em conjuntos de tabelas $2 \times 2$ e o teste exato de Fisher (versão exata do teste Qui-quadrado), uma vez que em todas as tabelas sempre tínhamos pelo menos uma célula com frequência inferior a 5 .

\section{Resultados}

São descritos a seguir os resultados obtidos entre as mulheres com excelência criativa e não reconhecidas por excelência criativa na aplicação da Escala Estilos de Pensar e Criar. Os resultados apresentados na Tabela 1 mostram que as mulheres excelentes criativas/premiadas obtiveram médias maiores no Estilo Emocional Intuitivo, enquanto as não excelentes criativas conseguiram melhores médias no Estilo Relacional Divergente. Entretanto, verificou-se que não houve diferenças significativas entre o grupo de mulheres nos cinco estilos de pensar e criar. 
Tabela 1 - Médias, desvios padrões e comparaçào das médias dos fatores da Escala de Estilos de Pensar e Criar entre premiadas e nào premiadas

\begin{tabular}{ccccccc}
\hline Fator & Grupo & N & Média & Desvio padrão & U-Mann Whitney & $p$ \\
\hline CR & Premiadas & 11 & 85,27 & 5,74 & 47,00 & 0,848 \\
& Nào premiadas & 9 & 85 & 3,57 & & \\
EI & Premiadas & 11 & 116,54 & 13,39 & 26,00 & 0,073 \\
& Nào premiadas & 9 & 101,33 & 17,02 & & \\
IT & Premiadas & 11 & 101,9 & 12,13 & 39,00 & 0,425 \\
& Nào premiadas & 9 & 97,22 & 11,87 & & \\
LO & Premiadas & 11 & 104,72 & 14,79 & 41,50 & 0,542 \\
& Nào premiadas & 9 & 110,55 & 11,38 & & \\
RD & Premiadas & 11 & 110,63 & 21,08 & 41,50 & 0,541 \\
& Nào premiadas & 9 & 111,11 & 8,63 & & \\
\hline
\end{tabular}

$\mathrm{CR}=$ Cauteloso Reflexivo; EI= Emocional Intuitivo; IT = Inconformista Transformador;

LO= Lógico Objetivo; RD= Relacional Divergente

A fim de estudar se existiam correlações significativas entre os estilos de pensar e criar e a Produção Criativa das mulheres excelentes criativas/premiadas e não premiadas foi utilizado a Correlação por Postos de Spearman como pode ser visto abaixo na Tabela 2.

Tabela 2 - Correlação por Postos de Spearman entre fatores da Escala de Estilos de Pensar e Criar e a Produção Criativa das premiadas e não premiadas

\begin{tabular}{ccccccl}
\hline Fator & $\begin{array}{c}\text { Produção não } \\
\text { reconhecida }\end{array}$ & $p$ & $\begin{array}{c}\text { Produção } \\
\text { reconhecida }\end{array}$ & $p$ & $\begin{array}{c}\text { Produção } \\
\text { Total }\end{array}$ & $p$ \\
\hline CR & $-0,278$ & 0,236 & 0,066 & 0,781 & $-0,241$ & 0,306 \\
EI & 0,532 & $0,016^{*}$ & 0,270 & 0,249 & 0,587 & $0,007^{* *}$ \\
IT & 0,181 & 0,445 & 0,068 & 0,774 & 0,175 & 0,461 \\
LO & $-0,270$ & 0,249 & $-0,060$ & 0,802 & $0-, 279$ & 0,233 \\
RD & 0,025 & 0,917 & 0,087 & 0,716 & 0,024 & 0,919 \\
\hline
\end{tabular}

CR= Cauteloso Reflexivo; EI- Emocional Intuitivo; IT- Inconformista Transformador;

$\mathrm{LO}=$ Lógico Objetivo; $\mathrm{RD}=$ Relacional Divergente

${ }^{*} p<0,05 ;{ }^{* *} p<0,01$

Os resultados apresentados na Tabela 2 indicam que somente o fator Emocional Intuitivo possui correlação significativa com a produção não reconhecida e correlação altamente significativa com a produção total.

Em seguida são examinados os resultados obtidos com as categorias retiradas das respostas da Análise de Conteúdo conseguidos por meio das entrevistas, apresentados na Tabela 3. 
Tabela 3 - Comparaçào das categorias da análise de conteúdo entre premiadas e não premiadas

\begin{tabular}{lccc}
\hline Categoria & $\chi^{2}$ & $\mathrm{gl}$ & $\mathrm{p}$ \\
\hline 1.Brincadeiras na infância & 0,0003 & 1 & 0,9862 \\
2.Comportamento na infầncia & 0,3762 & 1 & 0,5397 \\
3.Comportamento na adolescência & 0,0027 & 1 & 0,9584 \\
4.Interesse pela área de atuaçào & 0,7919 & 1 & 0,3735 \\
5.Mentores & 0,1335 & 1 & 0,7149 \\
6a.Características pessoais cognitivas & 19,8442 & 1 & $<0,001^{* * *}$ \\
6b.Características de personalidade & 19,0302 & 1 & $<0,001^{*} * *$ \\
7a.Motivação intrínseca & 3,9649 & 1 & $0,0465^{*}$ \\
7b.Motivação extrínseca & 1,5117 & 1 & 0,2189 \\
8.Condições que influem no processo criativo & 7,1140 & 1 & $0,0076^{* * *}$ \\
9.Fatores ambientais favoráveis à criatividade & 6,3242 & 1 & $0,0119^{*}$ \\
10.Barreiras & 0,7438 & 1 & 0,3885 \\
11.Administração vida pessoal e profissional & 0,1734 & 1 & 0,6771 \\
12.Desafio(s) atual(is) & 0,0466 & 1 & 0,8291 \\
13.Tempo livre & 5,2740 & 1 & $0,0216^{*}$ \\
14a.Identificaçào de jovens talentosos na área & 0,0000 & 1 & 1,0000 \\
14b.Características de jovens talentosos na área & 1,2492 & 1 & 0,2637 \\
14c.Diferença de gênero entre jovens talentosos & 0,0000 & 1 & 1,0000 \\
15a.Valores intelectuais p/ criatividade na carreira & 1,1782 & 1 & 0,2777 \\
15b.Valores personalidade p/ criatividade na carreira & 0,0817 & 1 & 0,7750 \\
15c.Valores sociais p/ criatividade na carreira & 0,8267 & 1 & 0,3632 \\
15d.Diferença de gênero na carreira & 0,3497 & 1 & 0,6270 \\
\hline \# & & &
\end{tabular}

É possível observar na Tabela 3 que houve diferenças altamente significativas entre as mulheres excelentes criativas/premiadas e não excelentes em criatividade (não premiadas) para as seguintes categorias: Características pessoais cognitivas (6a na tabela) $\left(X^{2}=19,8442, p<0,001\right)$ e Características de personalidade (6b na tabela) $\left(X^{2}=19,0302, p<0,001\right)$, tendo o grupo de premiadas obtido maiores resultados do que as não premiadas. A subcategoria que se sobressaiu em Características pessoais cognitivas foi Originalidade $\left(X^{2}=0,0001, p<0,001\right)$ e nas Características de personalidade foram as subcategorias Liderança $\left(X^{2}=0,0141, p<0,05\right)$ e Sensibilidade Interna/Empatia/Intuição $\left(X^{2}=0,0281, p<0,05\right)$ para as excelentes criativas/premiadas.

$\mathrm{Na}$ categoria Motivação intrínseca ( $7 a$ na tabela) que apresenta as subcategorias aperfeiçoamento contínuo, desenvolvimento potencial, missão criativa/paixão pelo que faz, curiosidade e necessidade interna, as mulheres excelentes criativas/premiadas obtiveram maiores pontuações significativamente diferentes das não premiadas $\left(x^{2}=3,9649, p<0,05\right)$. 
Nota-se também, na Tabela 3, diferença altamente significativa entre as mulheres excelentes criativas/premiadas e não premiadas na categoria Condições que influenciam no processo criativo $\left(X^{2}=7,1140, p<0,01\right)$, com resultados maiores às excelentes criativas/premiadas. A subcategoria Processo de incubação $\left(X^{2}=0,0236, p<0,01\right)$ da categoria Condições que influem no processo criativo ressaltou-se entre as brasileiras excelentes criativas/premiadas.

Além disso, ocorreram diferenças significativas $\left(x^{2}=6,3242, p<0,05\right)$ a favor das mulheres excelentes criativas/premiadas na categoria Fatores ambientais favoráveis à criatividade ( 9 na tabela), que envolve as subcategorias diversidade sociocultural, socialização, modelo do pai e modelo da mãe.

$\mathrm{Na}$ categoria Tempo livre (13 na tabela) ocorreram diferenças significativas $\left(x^{2}=5,2740, p<0,05\right)$ entre os dois grupos, com as excelentes criativas/premiadas obtendo as maiores pontuações. A subcategoria que sobressaiu-se na categoria Tempo livre foi Atividades Físicas $\left(X^{2}=0,0047, p<0,01\right)$ a favor das mulheres excelentes criativas/premiadas.

\section{Discussão}

O presente estudo buscou investigar os estilos de pensar e criar, e verificar as diferenças nos fatores ambientais e psicológicos que influenciam a excelência criativa de mulheres brasileiras em diferentes áreas. Os resultados da Escala Estilos de Pensar e Criar indicaram que não houve diferenças significativas entre as mulheres excelentes criativas/premiadas e não excelentes criativas em nenhum dos estilos, o que ocorreu provavelmente pela quantidade reduzida de participantes. Estes resultados contrariam a literatura referente as características esperadas às pessoas criativas, tais como a independência de julgamento social e o questionamento (Cotec, 2012; Patterson, Kerrin, \& Gatto-Roissard, 2012) e a originalidade (Rieger e Blaubergs, 1979) inerentes ao Estilo InconformistaTransformador. Também a intuição, a flexibilidade de pensamento e a capacidade de liderança presentes nestas pessoas (Dacey, 1998; Morais, 2001; Runco \& Pritzker, 2011; Wechsler, 2008a) e que caracterizam o Estilo Relacional-Divergente. Por sua vez, os resultados também contradizem a teoria de Kirton $(1976,1994)$, pois para ele os indivíduos inovadores são percebidos como contestadores, indisciplinados, pensadores, criadores, visionários, gostam de arriscar-se com ideias diferentes e tendem a ignorar hábitos e padrões, ao contrário do que é apresentado pelo Estilo Cauteloso-Reflexivo. 
Sobre a correlação entre os fatores da Escala Estilos de Pensar e Criar e os tipos de Produção Criativa, verificou-se que somente o fator Emocional Intuitivo possui correlação significativa com a produção não reconhecida e correlação altamente significativa com a produção total. Wechsler (2006) verificou correlações significativas entre os estilos e a produção criativa.

Quanto as categorias da Análise do Conteúdo, ocorreram diferenças altamente significativas entre as mulheres excelentes criativas e não excelentes criativas na categoria Características Pessoais Cognitivas, tendo o grupo de excelentes criativas/premiadas obtido maiores resultados do que as não excelentes criativas e sobressaindo a subcategoria originalidade. A originalidade foi uma das características mencionadas como inerente às mulheres altamente criativas (Rieger e Blaubergs, 1979).

$\mathrm{Na}$ categoria Características de Personalidade houve diferença altamente significativa entre os dois grupos, tendo o grupo de excelentes criativas/premiadas obtido maiores resultados do que as não excelentes criativas. Nessa categoria houve destaque para as subcategorias Liderança e Sensibilidade Interna/Empatia/Intuição. Estes dados estão de acordo com os estudos biográficos de pessoas eminentemente criativas de Barron e Harrington (1981), Plucker e Renzulli (1999) em que foram verificadas a capacidade de liderança, a sensibilidade interna e externa dentre as características de personalidade pertencentes àquelas.

Quanto à categoria Motivação Intrínseca foi observada diferença significativa entre as excelentes criativas/premiadas e não premiadas, tendo as excelentes criativas apresentado maior motivação intrínseca com as subcategorias aperfeiçoamento contínuo, desenvolvimento potencial, missão criativa/paixão pelo que faz, curiosidade e necessidade interna. A motivação intrínseca refere ao engajamento e satisfação que $o$ indivíduo tem pela atividade, independentemente dos estímulos ambientais, que podem levá-lo ao desenvolvimento de habilidades de domínio e ao desenvolvimento da criatividade (Amabile, 1996).

Para a categoria Condições que Influem no Processo Criativo notou-se diferença altamente significativa entre os grupos, tendo o grupo de excelentes criativas/premiadas obtido maiores resultados do que as não premiadas e sobressaindo a subcategoria Processo de Incubação. A incubação é uma das fases cruciais do processo criativo, pois pode levar as pessoas criativas a descobertas relevantes (Sio \& Rudowicz, 2007).

Também foram verificadas diferenças significativas entre as mulheres excelentes criativas/premiadas e não premiadas na categoria Fatores Ambientais Favoráveis à Criatividade com as subcategorias diversidade sociocultural, socialização, modelo do pai e da mãe. As mulheres excelentes criativas alcançaram maiores resultados nesta 
categoria. Chagas e Fleith (2011) observaram em estudo com jovens talentosos que a família é a causa de maior impacto sobre o desenvolvimento deles. Também o comportamento criativo dos pais e o fator multicultural familiar predizem a criatividade de seus descendentes (Chang et al., 2014; Leung et al., 2008), assim como as atitudes dos pais frente aos filhos (Alencar \& Fleith, 2003; Krumm, Vargas-Rubilar, \& Gullón, 2013). Por outro lado, Wechsler e Guerreiro (1986) verificaram em pesquisa com mulheres criativas brasileiras que elas apresentavam estados de conflito na identificação com a mãe.

Na categoria Tempo Livre houve diferença significativa entre os dois grupos, com as mulheres excelentes criativas/premiadas tendo obtido melhores resultados e com destaque para a subcategoria Atividades Físicas. A alta energia psíquica e física presente na pessoa criativa que a faz trabalhar por longas horas (Csikszentmihalyi, 1997) provavelmente é utilizada também em atividades físicas.

Ao analisar os resultados deste estudo, conclui-se que existem diferenças entre as mulheres com excelência criativa e aquelas não reconhecidas por sua criatividade. Assim sendo, é importante conhecer os fatores que auxiliam o alcance da excelência em criatividade. Por outro lado, ao considerar a idade média das participantes excelentes criativas/premiadas que é de 49 anos, notase que as mesmas foram criadas dentro de culturas machistas e a sociedade ainda luta contra o machismo, onde a mulher ganha menos do que o homem, gasta mais tempo cuidando dos filhos e dos afazeres domésticos, aspectos estes que dificultam 0 seu desenvolvimento profissional. E essa luta da mulher pelo seu reconhecimento pode influenciar no aparecimento de certas características nas mulheres excelentes criativas.

A pesquisa teve algumas limitações como a representatividade da amostra ser específica do Estado de São Paulo, não possibilitando generalizar os resultados encontrados para outras regiões do país. Também sobre a amostra, nota-se a não equivalência na quantidade de participantes excelentes criativas e não excelentes criativas, predominando as excelentes criativas, o que aconteceu pela dificuldade de se encontrar mulheres não premiadas com o mínimo de experiência em áreas que correspondessem àquelas das excelentes criativas/premiadas e que concordassem em cooperar com o estudo.

No que refere aos instrumentos aplicados, a Escala Estilos de Pensar e Criar foi o único instrumento que não conseguiu discriminar as mulheres excelentes criativas das não excelentes criativas, provavelmente devido a pequena quantidade de participantes. Portanto, uma amostra com maior número de mulheres nos grupos das excelentes criativas e não excelentes criativas seria necessária para melhor avaliar seus estilos de pensar e criar. Além disso, a 
pesquisadora sugere maior quantidade possível de participantes premiadas e não premiadas a fim de que se verifique mais adequadamente as dimensões cognitivas, afetivas e ambientais que interferem na expressão criativa.

\section{Referências}

Alencar, E. M. L. S., \& Fleith, D. S. (2003). Criatividade: múltiplas perspectivas (3a. ed.) Brasília: EdUnB.

Amabile, T. M. (1996). Creativity in Context. Oxford: Westview Press. Bardin, L. (2011). Análise de conteúdo. Lisboa: Edições 70.

Barron, F., \& Harrington, D. M. (1981). Creativity, intelligence and personality. Annual Review of Psychology, 32, 439-476.

Chagas, J. F., \& Fleith, D. S. (2011). Perfil de adolescentes talentosos e estratégias para o seu desenvolvimento. Psicologia: Teoria e Pesquisa, 27(4), 385-392.

Chang, J. H., Hsu, C. C., Shih, N. H., \& Chen, H. C. (2014). Multicultural Families and Creative Children. Journal of CrossCultural Psychology, 45(8), 1288-1296.

Cianciolo, A. T., Grigorenko, E. L., Jarvin, L., Gil, G., Drebot, M. E., \& Sternberg, R. J. (2006). Practical intelligence and tacit knowledge: Advancements in the measurement of developing expertise. Learning and Individual Differences, 16(3), 235-253.

Cotec (2012). La persona protagonista de la innovación. Recuperado em 20 de maio, 2012, de http://www.oei.es/salactsi/personas.pdf

Csikszentmihalyi, M. (1997). Creativity: flow and the psychology of discovery and invention. New York: Harper Collins.

Dacey, J. S. (1998). Understanding creativity: the interplay of biological, psychological, and social factors. San Francisco: Jossey-Bass.

Dessen, M. A. (1997). Desenvolvimento familiar: transição de um sistema triádico para poliádico. Temas em Psicologia, 3, 51-61.

Ericsson, K. A., \& Lehmann, A. C. (1996). Expert and exceptional performance: Evidence of maximal adaptation to task constraints. Annual Review of Psychology, 47, 273-305.

Garcia-Santos, S. C., Almeida, L. S., \& Werlang, B. S. G. (2012). Excelência Humana: A contribuição da personalidade. Paidéia, 22(5), 251-259.

Kirton, M. (1976). Adaptors and innovators: a description and measure. Journal of Applied Psychology, 61(5), 622-629.

Kirton, M. (1994). Adaptors and Innovators - Styles of Creativity and Problem Solving. London: Routledge 
Krumm, G., Vargas-Rubilar, J., \& Gullón, S. (2013). Estilos parentales y creatividad en niños escolarizados. Psicoperspectivas, 12(1), $161-182$.

Leung, A. K. Y., Maddux, W. W., Galinsky, A. D., \& Chiu, C. Y. (2008). Multicultural experience enhances creativity: the when and how. American Psychologist, 63(3), 169-181.

Martins, E. (2009). Estilos de pensar e criar em gerentes e subgerentes de micro e pequena empresas. Dissertação de Mestrado. Campinas: Pontifícia Universidade Católica de Campinas.

Morais, M. F. (2001). Definição e avaliação da criatividade. Braga: Universidade do Minho.

Mundim, M. C. B., \& Wechsler, S. M. (2007). Estilos de pensar e criar em gerentes organizacionais e subordinados. Boletim de psicologia, 57(126), 15-32.

Oliveira, M. A. D., \& Nakano, T. D. C. (2014). Criatividade e resiliência na vida de Nise da Silveira. Estudos e Pesquisas em Psicologia, 14(2), 497-523.

Patterson, F, Kerrin, M., \& Gatto-Roissard, G. (2012). Characteristics $\&$ Behaviours of Innovative People in Organisations. Recuperado em 20 de maio, 2012, de http://www.nesta.org.uk/library/documents/characteristicsinno-orgs-interim-report.pdf

Plucker, J., \& Renzulli, J. S. (1999). Psychometric approaches to the study of human creativity. Em R. J. Sternberg (Ed.), Handbook of creativity (pp. 35-60). New York: Cambridge University Press.

Puccio, G. J., Murdock, M. C., \& Mance, M. (2007) Creative Leadership: Skills that Drive Change. San Diego, CA: Sage.

Ramos, P. C. C. (2008). Pai, mãe e família: concepções de crianças pré-escolares. Dissertação de Mestrado, Universidade de Brasília, Brasília, DF, Brasil.

Rieger, M. P., \& Blaubergs, M. S. (1979). Creative women: their potential, personality, and productivity. Canadian Women's Studies, 7(3), 16-21.

Runco, M. A. (2006). The development of children's creativity. In B. Spodek, \& O. N. Saracho (Eds.), Handbook of research on the education of young children (pp. 121-131) New York: Routledge.

Runco, M. A. (2007). Creativity - Theories and Themes: Research, Development and Practice. California: Elsevier.

Runco, M. A., \& Pritzker, S. R. (Eds.). (2011). Encyclopedia of creativity. California: Elsevier, $2^{\mathrm{a}}$ Edition. Recuperado em 15 de maio, 2013, de http://books.google.com.br/books?id=dI6mI7kg400C\&printsec $=$ frontcover $\& \mathrm{hl}=\mathrm{pt}-\mathrm{BR} \# \mathrm{v}=$ onepage $\& \mathrm{q} \& \mathrm{f}=$ false 
Simonton, D. K. (2008). Scientific Talent, Training, and Performance: Intellect, Personality, and Genetic Endowment. Review of General Psychology, 12(1), 28-46.

Sio, U. N., \& Rudowicz, E. (2007). The role of an incubation period in creative problem solving. Creativity Research Journal, 19(2-3), 307-318.

Sternberg, R. J. (2001). Giftedness as developing expertise: A theory of the interface between high abilities and achieved excellence. High Ability Studies, 12(2), 159-179.

Torrance, E. P. (1981). Empirical validation of criterion-reference indicators of creative ability through a longitudinal study. Creative Child and Adult Quarterly, 6,136-140.

Trost, G. (2000). Prediction of excellence in school, higher education, and work. In K. A. Heller, F. J. Mönks, R. J. Sternberg, \& R. F. Subotnik (Eds.), International handbook of giftedness and talent (2nd ed., pp. 317-325). Oxford, England: Elsevier Science.

Wechsler, S., \& Guerreiro, M. C. R. F. (1986). Fatores biográficos influenciantes na criatividade da mulher brasileira. Educação e Realidade, 11(2), 81-86.

Wechsler, S. M. (1999). Avaliação da criatividade: um enfoque multidimensional. In S. M. Wechsler, \& R. S. L. Guzzo (Orgs.) Avaliação psicológica: perspectiva internacional (pp. 231-260). São Paulo: Casa do Psicólogo.

Wechsler, S. M. (2004). Avaliação da criatividade por palavras Teste de Torrance. Lamp/Puc-Campinas: Campinas - $2^{a}$ edição.

Wechsler, S. M. (2006). Estilos de pensar e criar (manual). Campinas: IDB Impressão Digital do Brasil.

Wechsler, S. M. (2008a). Criatividade: Descobrindo e Encorajando. Campinas: PSY.

Wechsler, S. M., Vendramini, C. M. M., \& Oakland, T. (2012). Thinking and Creative Styles: A Validity Study. Creativity Research J ournal, 24(2-3), 235-242.

Wechsler, S. M., Romo, M., Morais, M. F., \& Ferreira, C. (2013). Caracterização da mulher criativa. (Trabalho não publicado).

\section{Endereço para correspondência \\ Maria Célia Bruno Mundim}

Pontifícia Universidade Católica de Campinas

Departamento de Pós-Graduação em Psicologia da PUC-Campinas

Avenida John Boyd Dunlop, s/n, Jardim Ipaussurama, CEP 13060-904, Campinas SP, Brasil

Endereço eletrônico: celiamundim@hotmail.com

\section{Solange Muglia Wechsler}

Pontifícia Universidade Católica de Campinas

Departamento de Pós-Graduação em Psicologia da PUC-Campinas

Avenida John Boyd Dunlop, s/n, Jardim Ipaussurama, CEP 13060-904, Campinas SP, Brasil 
Endereço eletrônico: wechsler@lexxa.com.br

Recebido em: 07/03/2015

Reformulado em: 25/06/2015

Aceito para publicação em: 03/09/2015

\section{Notas}

* Doutora em Psicologia pela Pontifícia Universidade Católica de Campinas.

** Docente associada do Programa de Pós-Graduação em Psicologia da PUCCampinas.

As autoras agradecem a Coordenação de Aperfeiçoamento de Pessoal de Nível Superior pelo financiamento desta pesquisa. 